Research Article

\title{
Plant Mediated Green Synthesis of Silver Nanoparticles Using Tecomella undulata Leaf Extract and Their Characterization
}

\author{
Sadhan Kumar Chaudhuri ${ }^{1}$, Shivani Chandela ${ }^{2}$, Lalit Malodia ${ }^{1}$ \\ ${ }^{1}$ Visual Camouflage Group, Defence Laboratory, Defence Research \& Development Organization, Ratanada Palace, Jodhpur, \\ Rajasthan, India \\ ${ }^{2}$ Lachoo Memorial College of Science and Technology, Sector-A, Shastri Nagar, Jodhpur, Rajasthan, India \\ Corresponding author: E-mail: skcdrdo@gmail.com
}

Received: Dec. 9, 2015; Accepted: Jan. 28, 2016; Published: Feb. 24, 2016.

Citation: Sadhan Kumar Chaudhuri, Shivani Chandela and Lalit Malodia. Plant Mediated Green Synthesis of Silver Nanoparticles Using Tecomella undulata Leaf Extract and Their Characterization. Nano Biomed. Eng. 2016 8(I), I-8.

DOI: $10.5101 /$ nbe.v8il.pI-8.

\begin{abstract}
Green synthesis of silver nanoparticles (AgNPs) was carried out using aqueous extract of Roheda (Tecomella undulata) at $60^{\circ} \mathrm{C}$ in orbital shaking incubator. The variation in $\mathrm{pH}$ values and colour changes were observed within few minutes during reduction of silver nitrate $(0.1$ to $1 \mathrm{mM}$ final concentration) in presence of plant extract and the capping of synthesized stable silver nanoparticles. The UV-Vis spectra of reaction mixture at different time intervals were recorded to monitor the formation of nanoparticles. The maximum absorption peak was observed near $430 \mathrm{~nm}$ indicating the formation of AgNPs. The particle size distribution was analysed through dynamic light scattering (DLS) and it was found that the peaks at $5.85 \mathrm{~nm}$ and $77.48 \mathrm{~nm}$. Polydisperse Index (PDI) of synthesized AgNPs is 0.378 indicating that nanoparticles are stable even after nine months storage and uniform size range. The stability of biogenic silver nanoparticles was monititored through zeta potential measurement. The surface properties and size of the nanoparticles were studied through scanning electron microscopy and atomic force microscopy. The purity of the synthesized nanoparticle was confirmed by electron dispersive X-ray spectroscopy (EDS). Atomic force microscopy images indicated that height of the particle ranges from 3-18 nm. The results of various techniques indicated that these are silver nanoparticles synthesized using leaf extract of Tecomella undulata.
\end{abstract}

Keywords: Biosynthesis; Silver nanoparticles; Tecomella undulata; UV-Vis spectra; DLS; SEM; EDS; AFM

\section{Introduction}

Over the past decade nanoscience and nanotechnology is a sprouting interdisciplinary field of research interspersing material science, bionanosciences and biotechnology. The synthesis of metal nanoparticles is an important topic of research in modern material science due to their distinctive potential in the fields of electronic, magnetic [1], optoelectronic [2], information storage [3] and drug delivery [4]. Nanocrystalline silver nanoparticles have found tremendous applications in the fields of solar energy [5], water treatment [6], medicine [7] and also as catalyst [8]. The increasing demand of eco-friendly approach must be accompanied by green synthesis procedure. 
Nanoparicles can be synthesized by chemical and physical methods, which are expensive, hazardous to environment and required high energy consumption. Biological methods using microorganisms [9], enzymes [10], fungus [11], plant extracts [12] have been suggested as possible eco-friendly alternative methods over chemical and physical methods. Nanoparticles synthesis using plant parts are advantageous over other biological process by eliminating the process of maintaining time consuming aseptic microbial culture. Nanoparticles produced by plant parts are more stable, the rate of synthesis is faster than that in the case of other organisms, low cost, eco-friendly and a single step method of biosynthesis process [13]. Many reports are available on plant mediated synthesis of silver nanoparticles, particularly leaf extracts of Azadiracta indica [14], Oscimum sanctum [15], Magnolia kobus [16], Mangifera indica [17], Calotropis gigantean [18], Annona squamosa [19] and seed extracts of Coriandrum sativum [20] pomegranate [21]. Biogenic synthesis of silver nanoparticles using fruit extract of Ficus carica and its antimicrobial activity also reported [22]. Recent investigation of cytotoxic assays indicated that silver nanoparticles synthesized from Scoparia dulcis exhibit a significant cytototoxic in A549 cells compared to PA-1 cell line in a dose dependent manner [23].

Tecomella undulata (family: Bignoniaceae) is a tree species that produces quality timber is also known as roheda, honey tree, desert teak, marwar teak (English), roheda (Hindi). Distribution of Tecomella undulata is restricted to the drier parts of the Arabian countries, southern Pakistan and Northwest India up to an elevation of 1200 meters. In India, it occurs naturally in Maharashtra, Gujarat, Rajasthan, Punjab and Haryana. The methanolic extracts of Tecomella undulata are known for their analgesic and antiinflammatory potential, disorders, epilepsy, cholera, pain, urinary problems, malaria, heart problems, and sexually transmitted diseases. It was traditionally used in medicinal ailments like cancer, snake bite, skin disorders, gastrointestinal disorders, respiratory tract disorders, gynecological disorders, hepatic transmitted diseases. The plant is also used for treating liver and spleen diseases, tumours, conjunctivitis, hepatosplenomegaly, syphilis, gonorrhea, hepatitis, as a blood purifier and in wound healing. Compounds such as naphthaquinone derivative, iridoid glucoside, phytosterol, fatty alcohol, flavonols, flavonoid glucoside and triterpenoids have been reported.
Anti HIV, anti bacterial, anti microbial, immune modulator, analgesic and hepatoprotective activities have been reported from its various aerial parts [24]. The phytochemical analysis revealed the presence of five compounds i.e. alkaloids, flavonoids, saponins, steroids, tannins [25].

Iron oxide and zinc oxide nanoparticles have potential for increased seedling growth in various agricultural crops like peanut [26], mung and gram [27]. Silver nanoparticles also showed faster and increased seed germination and plant height in an endemic and endanger medicinal tree [28]. Biogenic silver nanoparticles enhanced seed germination and seedling growth in Vigna radiata and Cicer arietinum [29], Pennisetum glaucum [30] and other crop (corn, watermelon and zucchini) plants [31]. There is not a single report of silver nanoparticles effects on tree seedlings growth in nursery stage. Therefore the present investigation was made to synthesize silver nanoparticles by using hot desert plant leaf extract of Tecomella undulata. First time we are reporting that like other plant leaf extracts, Tecomella leaf extract has a potential to synthesize silver nanoparticles.

\section{Experimental}

\section{Materials and Methods}

\section{Collection of plant material}

The fresh leaves of Roheda (Tecomella undulata) plants available in Defence Laboratory campus, Jodhpur, India were collected in polythene packet.

\section{Preparation of leaf extract}

$20 \mathrm{~g}$ of fresh leaves thoroughly washed in tap water followed by Milli-Q water to remove any dust particles, dried with water absorbent paper and chopped into small pieces with scissor. Then chopped leaves were blended in mixer grinder for few second with $10 \mathrm{ml}$ of sterile Milli-Q water and take the paste with the help spatula. $90 \mathrm{ml}$ of Milli-Q water was added to leaf extract paste in a $500 \mathrm{ml}$ Erlenmeyer flask and placed in orbital shaker incubator at $60{ }^{\circ} \mathrm{C}$ with constant shaking at $120 \mathrm{rpm}$ for $10 \mathrm{~min}$. After cooling at room temperature and filtering through Whatman No.1 paper the leaf extract was stored in refrigerator $\left(4-7{ }^{\circ} \mathrm{C}\right)$ for further experiments. All the glass goods used were cleaned in chromic acid and autoclaved. 


\section{Synthesis of silver nanoparticles}

The AR grade silver nitrate $\left(\mathrm{AgNO}_{3},\right)$ was procured from Emerck Germany and plant extract used for the reduction of $\mathrm{Ag}^{+}$ions to $\mathrm{Ag}^{0}$ at $60{ }^{\circ} \mathrm{C}$ in a constant shaking at $120 \mathrm{rpm}$ in orbital shaking incubator. In a typical experiment, leaf extracts $(3 \mathrm{ml}$ and $6 \mathrm{ml})$ were added to $300 \mathrm{ml}$ of final concentration of $0.1 \mathrm{mM}$ and $1.0 \mathrm{mM} \mathrm{AgNO}_{3}$ dissolved in Milli-Q-water.

\section{Instrumentation}

\section{$\mathrm{pH}$ analysis}

Silver nitrate aqueous solutions $(0.1 \mathrm{mM}$ and 1 $\mathrm{mM}$ ) show pH 6.00 and 5.91 respectively. Leaf extract $\mathrm{pH}$ was 5.49 (Table 2). The changed $\mathrm{pH}$ of reaction mixtures were determined using digital $\mathrm{pH}$ meter (Eutech Cybersacn pH 300), during synthesis of silver nanoparticles.

\section{UV-Vis spectral analysis}

The reduction in silver ion was monitored by measuring the UV-Vis spectroscopy of the reaction medium after diluting small aliquot of the reaction mixture 10 times diluted with Milli-Q water to avoid the error due to high optical density of reaction mixture at different intervals after $15 \mathrm{~min}$. UV-Vis spectral analysis was done by using UV-Vis-NIR spectrophotometer (Ocean Optics).

\section{Dynamic Light Scattering analysis}

Particle size distribution and average size of silver nanoparticles was obtained through particle size analyzer (Malvem zetasizer, Nano Z500, UK). The sample holder temperature was maintained at $25^{\circ} \mathrm{C}$. The measurements depend on the size particle core, the size of surface structure, particle concentration and the type of ion in the mixture. The zeta potential of the synthesized silver nanoparticles was determined in water as dispersant [32].

\section{Scanning Electron Microscopy analysis}

Scanning electron microscopy (SEM) analysis was carried out using ZISS model machine. Thin film of the sample was prepared on carbon coated tape by adhering small amount of dried fine powder of the sample on the grid, the extra sample was removed with the help of blotting paper and the film on the SEM grid were allowed to dry by putting it under a mercury lamp for $5 \mathrm{~min}$. The SEM analysis was used to determine the structure of the reaction products during biosynthesis of silver nanoparticles

\section{Energy Dispersive X-ray Spectroscopic analysis}

EDS analysis was carried out to determine the chemical purity, elemental composition and stoichiometry of the synthesized silver nanoparticles.

\section{Atomic Force Microscopy analysis}

The atomic force microscopy (AFM) is one of the foremost tools for imaging, measuring and manipulating material at nanoscale. It offers a capability of three dimensional visualization and both qualitative and quantitative information on many physical properties including size, morphology, surface texture and roughness. The liquid sample having silver nanoparticle was spread on mica sheet, dried at $35^{\circ} \mathrm{C}$ incubator and scanned with semi contact mode with close loop $3 \times 3 \mu \mathrm{m}$ scanner (Solver Model, NTMDT, Russia).

\section{Results and Discussion}

\section{Colour change}

Incubation of reaction mixture in orbital shaker incubator at $60{ }^{\circ} \mathrm{C}$, a change of colour from pale yellow to reddish brown was observed (Fig. 1) within few minutes. The change of colour indicates that the formation of silver nanoparticles. The intensity of colour gradually increased (Table 1) with increasing time and concentration of $\mathrm{AgNO}_{3}$.

\section{Variation in $\mathrm{pH}$ during synthesis of silver nanoparticles}

The $\mathrm{pH}$ of the reaction mixture decreased from 6.5 to 5.5 in presence of Tecomella leaf extract indicating that reduction of $1.0 \mathrm{mM} \mathrm{AgNO}_{3}$ during formation of silver nanoparticles (Table 2). Reduction of $\mathrm{pH}$ during biogenic synthesis of silver nanoparticles was also reported in presence of Jamun (Syzygium cumini) leaf extract [33].

\section{UV-Vis spectral analysis}

The UV-Vis spectroscopy of the synthesized nanoparticles were in the range of 410-450 $\mathrm{nm}$. 


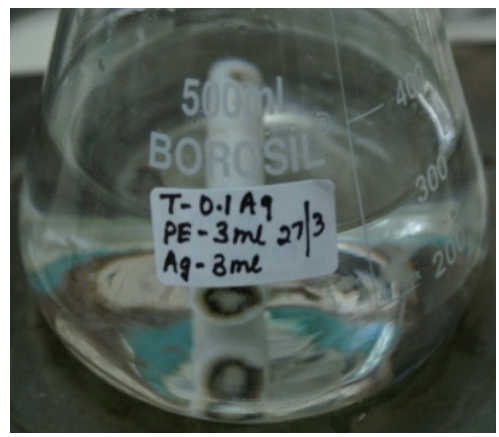

(a)

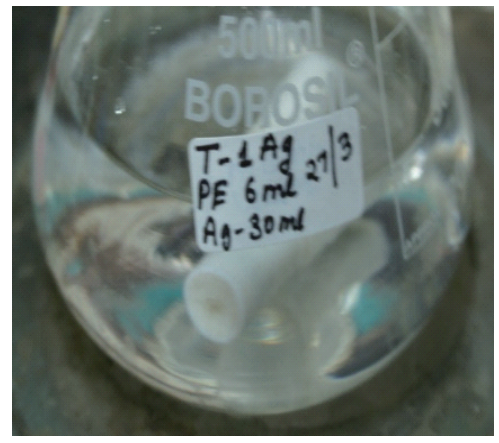

(d)

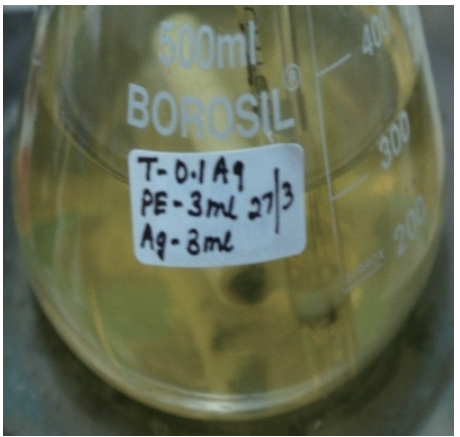

(b)

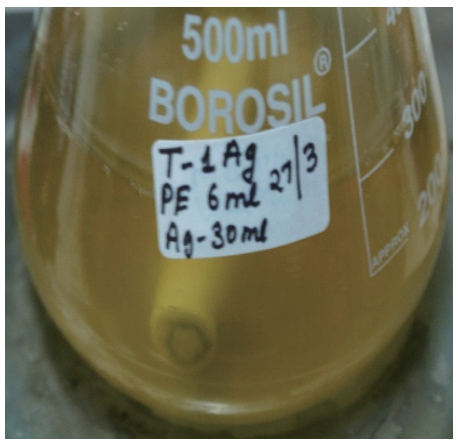

(e)

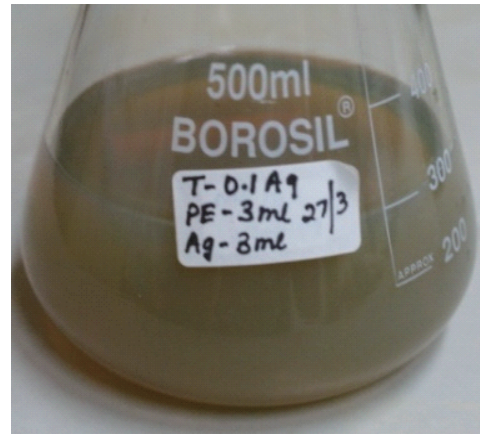

(c)

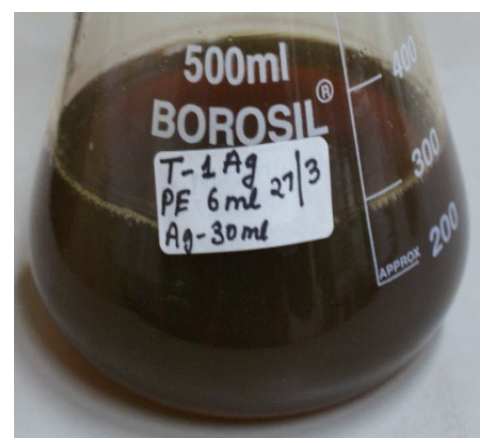

(f)

Fig. 1 Colour change of the reaction mixture indicating the formation silver nanopaticles in presence of Tecomella leaf extract. (a) \& (d): $0.1 \mathrm{mM} \& 1 \mathrm{mM} \mathrm{AgNO}_{3}$ solution (White colour). (b): $0.1 \mathrm{mM} \mathrm{AgNO}_{3}$ solution $+3 \mathrm{ml}$ leaf extract (Pale Yellow colour). (c): After four hours colour changed to light brownish colloidal solution indicating that formation silver nanoparticles. (e): $1.0 \mathrm{mM} \mathrm{AgNO}_{3}$ solution $+3 \mathrm{ml}$ leaf extract (Deep Yellow colour). (f): After four hours colour changed to deep brownish colloidal solution indicating that formation silver nanoparticles.

Table 1 Colour change of reaction mixture during formation of silver nanoparticles in presence of Tecomella leaf extract

\begin{tabular}{cccccc}
\hline Serial No & Solution & Before reduction & After reduction & Colour intensity & Time \\
\hline 1 & Tecomella leaf extract & Light Yellow & & & \\
2 & $0.1 \mathrm{mM} \mathrm{AgNO}_{3}$ & Pale yellow & light brownish & + & $4 \mathrm{hrs}$ \\
3 & $1.0 \mathrm{mM} \mathrm{AgNO}_{3}$ & Deep yellow & Dark brownish & +++ & $4 \mathrm{hrs}$ \\
\hline
\end{tabular}

Table 2 Reduction of $\mathrm{pH}$ in reaction mixture during formation of silver nanoparticles in presence of Tecomella leaf extract

\begin{tabular}{cccc}
\hline Serial No & Solution & Before reduction $(\mathrm{pH})$ & After reduction $(\mathrm{pH})$ \\
\hline 1 & $\begin{array}{c}\text { Techomella leaf extract } \\
\text { Leaf extract }+0.1 \mathrm{mM} \\
\mathrm{AgNO}_{3}\end{array}$ & 5.49 & 6.00 \\
3 & $\begin{array}{c}\text { Leaf extract }+1.0 \mathrm{mM} \\
\mathrm{AgNO}_{3}\end{array}$ & 6.55 & 5.50 \\
\hline
\end{tabular}

Tecomella leaf extract was able to synthesize the silver nanoparticles by the indication of suitable surface Plasmon resonance (SPR) with peaks near visible spectrum at $430 \mathrm{~nm}$ (Fig. 2). The peaks remain near $430 \mathrm{~nm}$ in different time intervals indicting the stability and uniformity of silver nanoparticles synthesis. The absorbance peak near $430 \mathrm{~nm}$, can be attributed to the plasmonic peak of silver nanoparticles, formed in the reaction mixture. There is no shift of peak position in different time intervals, the variation of maximum absorbance with increasing time indicated that the rate of formation of $\mathrm{Ag}$ nanoparticles.

\section{Dynamic Light Scattering analysis}

Fig. 3 shows the DLS pattern of suspension of silver nanoparticles synthesized using Tecomella leaf extract. The size distribution profile indicates that the size of 


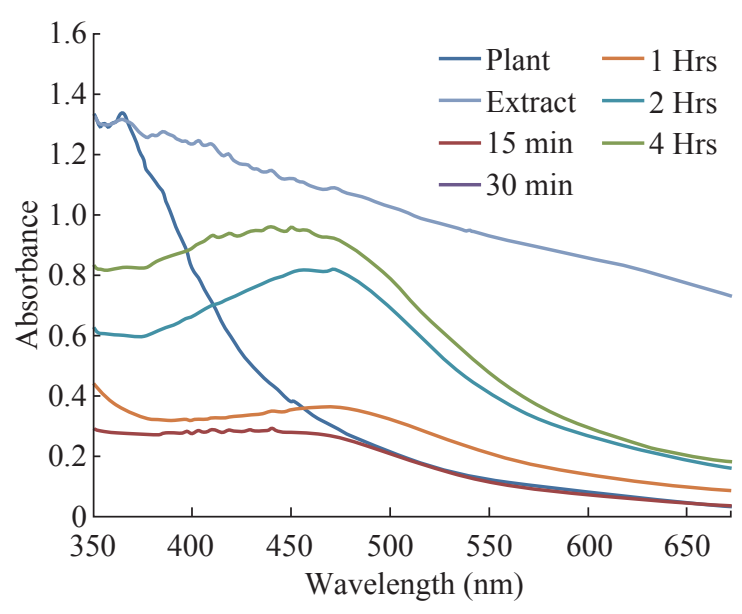

Fig. 2 UV-Visible spectra of silver nanoparticles at $1 \mathrm{mM}$ silver nitrate in different time course of reaction with Tecomella leaf extract.

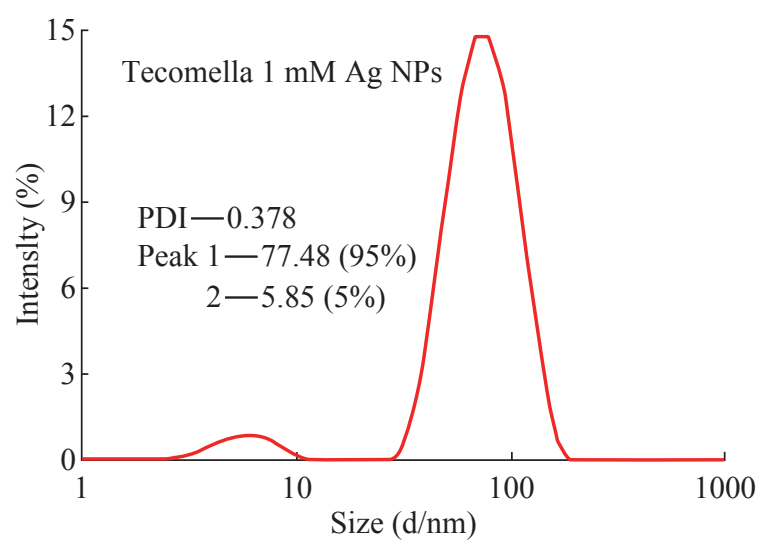

Fig. 3 DLS pattern of biogenic silver nanoparticles. these silver nanoparticles show two peaks at $5.8 \mathrm{~nm}$ (5\%) and $77.48 \mathrm{~nm}$ (95\%). Polydisperse index (PDI) silver nanoparticles suspension is 0.378 indicating that synthesized particles are good and uniform sizes. Fig. 4 shows that the measured zeta potential value of biosynthesized silver nanoparticles in the colloidal solution. The nanoparticles possess a negative zeta potential value of $-16.0 \mathrm{mV}$ indicated that even after the storage of nine months in room temperature these are highly stable due to electrostatic repulsive force. The high negative value confirms the repulsion among the particles and the negative indicates that nanoparticles are stable. Measurement of zeta potential is depends on the movement of nanoparticles under influence of an applied electric field. This movement depends upon surface charge and the local environment of the particle.

\section{Scanning Electron Microscopy analysis}

SEM analyses show the images of high density Ag NPs synthesized by Tecomella leaf extract (Fig. 5). From the given SEM images, it is concluded that the green synthesized silver nanoparticles are relatively spherical shape with diameter $32-46 \mathrm{~nm}$. Formation of silver nanoparticles was due to interactions of hydrogen bond and electrostatic interaction between the biomolecules capping with $\mathrm{Ag}^{0}$. The nanoparticles were not in direct contact even in the aggregated condition, indicating stabilization of nanoparticles by

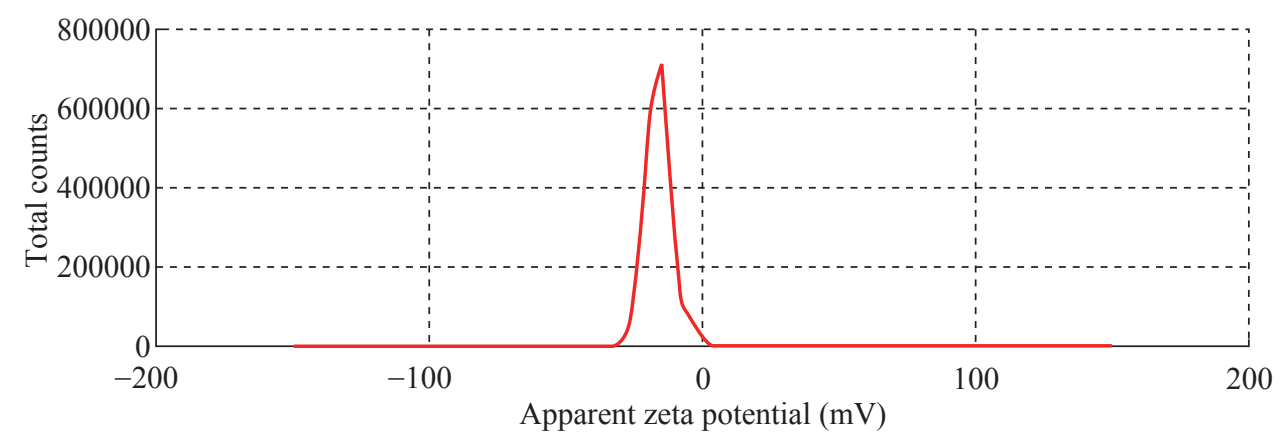

Fig. 4 Zeta potential measurement.

\begin{tabular}{|c|c|c|c|}
\hline Results & Mean (mV) & Area (\%) & St Dev $(\mathrm{mV})$ \\
\hline Zeta Potential (mv): -16.0 & Peak-1: -16.0 & 100.0 & 5.12 \\
\hline Zeta Deviation $(\mathrm{mV}): 5.12$ & Peak-2: 0.00 & 0.0 & 0.00 \\
\hline Conductivity (mS/cm): 0.365 & Peak-3: 0.00 & 0.0 & 0.00 \\
\hline Result Quality: Good & & & \\
\hline
\end{tabular}




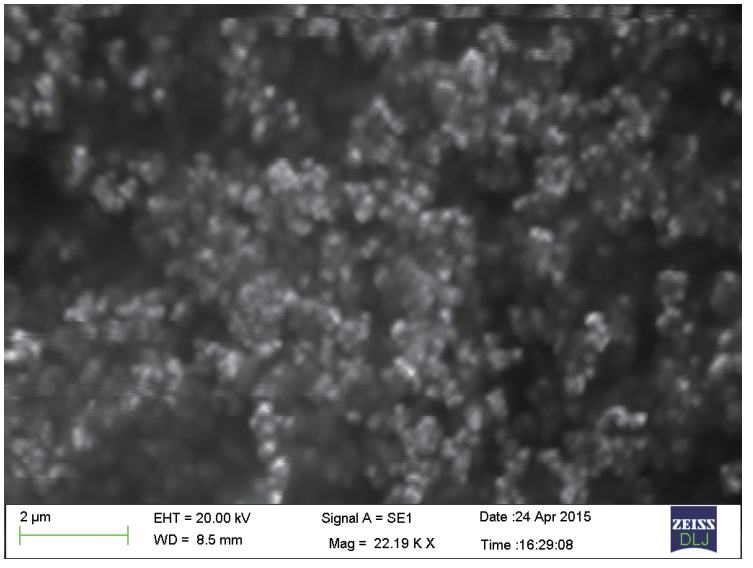

Fig. 5 SEM images of silver nanoparticles.

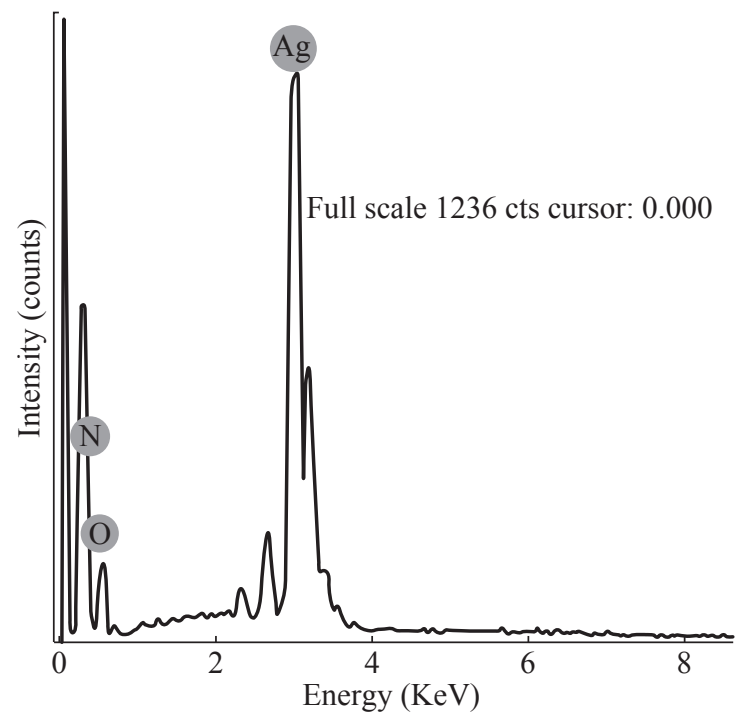

Fig. 6 Energy dispersive X-ray spectrum of synthesized silver nanoparticles.

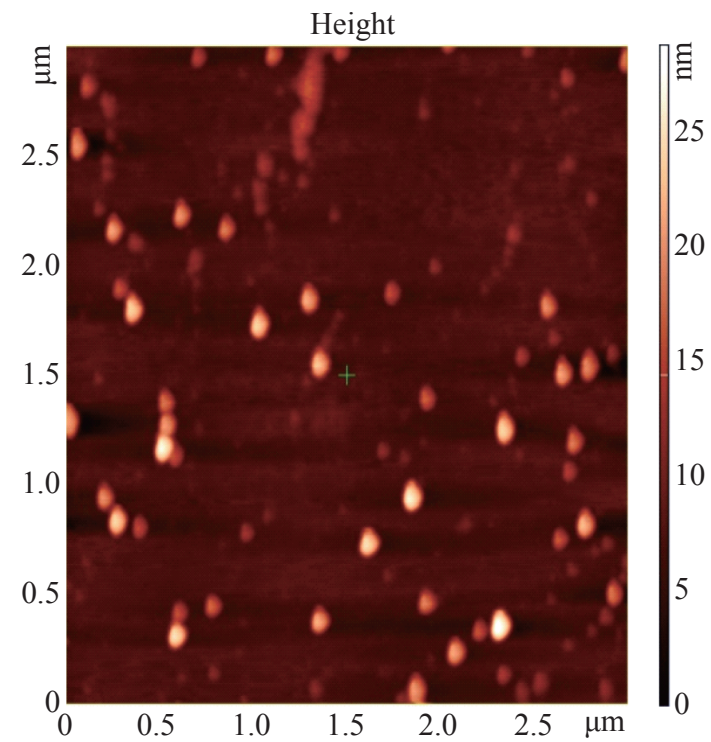

(a) capping agent.

\section{Energy Dispersive Spectroscopic analysis}

Energy dispersive X-ray spectroscopic (EDS) analysis was carried out to determine the chemical purity, elemental composition and stoichiometry of the synthesized silver nanoparticles which is shown in Fig. 6. The strong signal of silver has been detected in EDS indicating the purity of synthesized silver nanoparticles. The other signals available in EDS may be coming from the bioactive molecules in the Tecomella leaves extract. The strong peak (signal) of silver indicating that the biosynthesized nanoparticles are indeed made up of only silver (Fig. 6). The small peaks of oxygen $(\mathrm{O})$ and nitrogen $(\mathrm{N})$ might be coming from the chamber of EDS [23].

\section{Atomic Force Microscopy analysis}

To validate the surface morphology powder coated AFM, three dimensional images were taken in non contact mode (Fig. 7). Results showed variability in morphological features of Tecomella leaf extract mediated silver nanoparticles. Height of the particles ranges from 3 to $18 \mathrm{~nm}$ and width ranges from 1.7 to $0.049 \mathrm{~nm}$. It is evident from the AFM images that particles are uniform in size range and highly monodisperse nature.

Silver has long been recgnized as having inhibitory effect on microbes present in medical and industrial

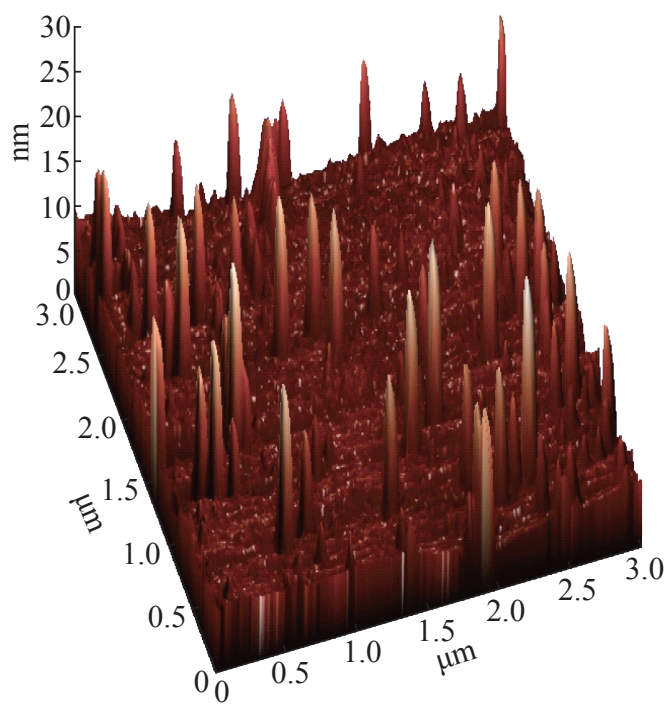

(b)

Fig. 7 (a) AFM 2D image; (b) Same field in 3D image. 
process [34]. The most important application of silver and silver nanoparticles is in medical industry such as tropical oinments to prevent infection against burn and open woonds. Furether these biologically synthesized nanoparticles were found highly toxic against different multidrug resistant human pathogens. The efficacy of of silver nanoparticles in the killing of cancer cells was also tested. The results indicated they are more effective in overian cancer cell line [23].

\section{Conclusions}

Synthesis of silver nanoparticles was quite stable without using any toxic chemicals as capping agent. Colour change visible due to the surface plasmon resonance during reaction bioactive compounds present in leaf extract of Tecomella undulata resulting in the synthesis of silver nanoparticles. The bio-molecules present in the Tecomella leaf extract are able to reduce silver nitrate and capping the silver nanoparticles at $60{ }^{\circ} \mathrm{C}$. Biosynthesis of silver nanoparticles using plant parts extract may be influenced directly or indirectly by phytochemicals in the leaf extracts such as phenols, flavonoids and antioxidants as well as the physicochemical factors governing the kinetics of the reaction. The route is preferably docile as it is ecofriendly, require less energy intensive process and it is cost effective. Moreover, it is an efficient way of waste biomass utilization for the biosynthesis of silver nanoparticles. Biosynthesized silver nanoparticles are stable in liquid suspension even after nine months, as the particle size and distribution remain unchanged. The stability of fungal extracellular protein mediated biosynthesized $\mathrm{ZnO}$ nanoparticles and enhanced growth effect in clusterbean is also reported [35]. The green synthesis approach towards the synthesis of silver nanoparticles has many advantages. So far in literature survey, its applications are restricted in antimicrobial activity [20,22], cytotoxicity assays $[23,36]$, and enhanced seedling growth in crop plants [31] but there is not a single report on its effect on tree seedling growth in nursery stage. Therefore, plant mediated biosynthesis of nanoparticles could be used for the study of faster tree seedling growth and development for arboriculture camouflage applications. With the huge plant diversity much more plant species are in way to be exploited and reported in future era towards rapid and single step protocol for the synthesis various types of metal nanoparticles with green principle. Biological synthesis of nanoparticles has upsurge in the field of nano-biotechnology to create novel materials that are eco-friendly, cost effective, stable nanoparticles with a great importance for wider applications in the areas of electronics, medicines, agriculture and forestry.

\section{Acknowledgement}

We acknowledge to Director, Defence Laboratory, Jodhpur, for providing infrastructure facilities and his keen interest on biosynthesis of nanoparicles for the development of fast growing stress tolerant tree saplings for military applications.

\section{References}

[1] T. Tuutijarvi, J. Lu, M. Sillanpaa, et al., As(V) adsorption on maghemite nanoparticles. J. Hazard. Mater. 2009, 166: $1415-1420$.

[2] K. Tanabe, Optical radiation efficiencies of metal nanoparticles for optoelectronic applications. Mater. Lett. 2007, 63: 4573- 4575.

[3] H.W. Zhang, Y. Liu, S.H. Sun, Synthesis and assembly of magnetic nanoparticles for information and energy storage applications. Front. Phys. 2010, 5: 347-356.

[4] D.R. Bhumkar, H.M. Joshi, M. Sastry, et al., Chitosan reduced gold nanoparticles as novel carriers for transmucosal delivery of insulin. Pharmaceutical Research, 2007, 24: 1415-1426.

[5] A.C. Arango, L.R. Jhonson, V.N. Bliznyuk, et al., Efficient titanium oxide/conjugated polymer photovoltaics for solar energy conversion. J. Adv. Mater. 2000, 12: 1689-1692.

[6] K. Dhermendra, J.B.Tewari, P. Sen, Application of nanoparticles in waste water treatment. World Applied Science J. 2008, 3: 417-433.

[7] Y.M. Jun, Y.M. Huh, J.S. Choi, Nanoscale size effect of magnetic nanocrystals and their utilization for cancer diagnosis via magnetic resonance imaging. J. Am. Chem. Soc. 2005, 127: 5732-5733.

[8] K. Tsujino, M. Matsumura, Morphology of nanoholes formed in silicon by wet etching in solution containing $\mathrm{HF}$ and $\mathrm{H}_{2} \mathrm{O}_{2}$ at different concentrations using silver nanoparticles as catalysts. Electrochim. J. Acta. 2007, 53: 28-34.

[9] A.K. Jha, K. Prasad, A.R. Kulkarni, Synthesis of $\mathrm{TiO}_{2}$ nanoparticles using microorganism. Colloid. Surface. B. 2009, 71: 226-229.

[10] I. Willner, R. Baron, B. Willner, Growing metal nanoparticles by enzymes. J. Adv. Mater. 2006, 18: 11091120.

[11] M. Jain, R. Kapadia, R.N. Jadeja, et al., Traditional uses, phytochemistry and pharmacology of Tecomella undulate - a review. Asian Pacific Journal of Tropical Biomedicine. 2012: S1918-S1923.

[12] A.K. Mittal, Y. Chisti, U.C. Banerjee, Synthesis of metallic nanoparticles using plant extract. Biotechnology Advances. 2013, 30: 346-356.

[13] V. Kumar, S.K. Yadav, Plant-mediated synthesis of silver and gold nanoparticles and their applications. J. Chem. Techonl. Biotechnol. 2009, 84: 151-157.

[14] S.S. Sarkar, A. Rai, A. Ahmad, et al., Rapid synthesis of $\mathrm{Au}, \mathrm{Ag}$ and bimetallic $\mathrm{Au}$ core-Ag shell nanoparticles using neem (Azadiracta indica) leaf broth. J. Colloid. 
Interface. Sci. 2004, 275: 496-502.

[15] C. Ramteke, T. Chabarti, B.K. Sarangi, et al., Synthesis of silver nanoparticles from aqueous extract of leaves of Ocimum sacnctum for enhanced antimicrobial activity. Journal of Chem. 2013; dx.doi.org/10.1155/3013/278925.

[16] Y.J. Song, H.K. Jang, B.S. Kim, Biological synthesis of silver nanoparticles using Magnolia kobus and Dipyros kaki leaf extract. Process Biochem. 2009, 44:1133-1138.

[17] V. Sarsar, K.K. Selwal, M.K. Selwal, Green synthesis of silver nanoparticles using leaf extract of Mangifera indica and evaluation their antimicrobilal activity. J. Microbiol. Biotech. Res. 2013, 3: 27-32.

[18] J. Sivakumar, C. Premkumar, P. Santhanam, et al., Biosynthesis of silver nanoparticles using Calotropis gigantean leaf. African Journal of Basic \& Applied Sci. 2011, 3: 265-270.

[19] S. Singaravelu, K. Ponnuchamy, L.P. Alagiyamanavalan, et al., Green simplistic biosynthesis of anti-bacterial silver nanoparticles using Annona squamosa leaf extract. Nano. Biomed. Eng. 2103, 5: 102-106.

[20] R.D. Manisha, R. Merugu, A.R. Vijaybabu, et al., Microwave assisted biogenic synthesis of silver nanoparticles using dried seed extract of Coriandrum sativum, characterization and antimicrobial activity. International J. Chem. Tech. Res. 2014, 6: 3957-3961.

[21] S. Chauhan, M.K. Upadhya, R. Narayan, et al., Phytofabrication of silver nanoparticles using pomegranate fruit seeds. International Journal of Nanomaterials and Biostructures 2011, 1: 17-21.

[22] K. Logaranjan, S. Devi, K. Pandian, Biogenic synthesis of silver nanoparticles using fruit extract of Ficus carica and study its antimicrobial activity. Nano. Biomed. Eng. 2012, 4: $177-182$.

[23] K. Khanra, S. Panja, I. Chaudhuri, et al., Evaluation of Antibacterial activity and cytotoxicity of green synthesized silver nanoparticles using Scoparia dulcis. Nano. Biomed. Eng. 2015, 7: 128-133.

[24] N. Jain, A. Bhargava, S. Mazumdar, et al., Extracellular biosynthesis and characterization of silver nanoparticles using Aspergillus flavus NJP08: a mechanism perspective. Nanoscale 2011, 3: 635-641.

[25] D.V. Easwarti, S.N. Suresh, P. Sagadevan, et al., Studies on phytochemical analysis and antioxidant activity of methanolic leaf Extract Tecomela undulata. Journal of Pharmaceutical and Biological Research 2014, 2: 143147.

[26] T.N.V.K.V. Prasad, P. Sudhakar, Y. Sreenivasulu, et al., Effect of nanoscale zinc oxide particles on the and yield of peanut. J. Plant. Nutri. 2012, 35: 905-927.

[27] M. Prasad, S.K. Dhoke, A.S. Khanna, Effect of nano$\mathrm{ZnO}$ particle suspension on growth of Mung (Vigna radiata) and gram (Cicer arietinum) seedling using plant agar methods. J. Nanotechnology 2011, doi $10.115 / 2011 / 696535$.

[28] N. Savithramma, S. Ankanna, G. Bhumi, Effect of nanoparticles on seed germination and seedling growth of Bosswella ovalifoliata - an endemic and endangered tree taxon. NanoVission 2012, 2: 61-68.

[29] S.S. Satish, G. Melchias, P. Ravikumar, et al., Biogenic silver nanoparticles synthesized by Euphorbia hirta enhance seed germination and eliminate microbial contamination. World J. Pharmacy \& Pharmaceutical Sci. 2014, 3: 784-794.

[30] A. Asra, S. Rao, Effect of nanosilver on seed germination and seedling growth in Pennisetum glaucum. J. Clus. Sci. 2015, 26: 693-701.

[31] Z.M. Almutairi, A. Alharbi, Effect of silver nanoparticles on seed germination of crop plants. J. Adv. Agriculture. 2015, 4: 280-285.

[32] K. Shameli, M.B. Ahmad, P. Shabanzadeh, et al., Effect of curcuma longa tuber powder extract on size of silver nanoparticles prepared by green method. Res. Chem. Intermed. 2013, doi: 10.1007/11164-013-1040-4.

[33] S. Behera, P.L. Nayak, In vitro antibacterial activity of green synthesized silver nanoparticles using jamun extract against multiple drug resistant bacteria. World J. Nano Sci. \& Technol. 2013, 2: 62-65.

[34] J.R. Morones, J.L. Elechiguerra, A. Camacho, et al., The bactericidal effect of silver nanoparticles. $J$. Nanotechnology 2005, 16: 2346-2353.

[35] R. Raliya, J.C. Tarafdar, $\mathrm{ZnO}$ nanoparticles biosynthesis and its effect on phosphorus-mobilzing enzyme secretion and gum content in clusterbean (Cyamopsis tetragonoloba L.). Agric. Res. 2013, 2: 48-57.

[36] P.V. Pulate, M.U. Ghurde, V.R. Deshmukh, Cytological effect of the biological and chemical silver nanoparticles in Allium cepa L. International J. Innovation in Bio-Sci. 2011, 1: 32-35.

Copyright $\subset$ 2016 Sadhan Kumar Chaudhuri, Shivani Chandela and Lalit Malodia. This is an open-access article distributed under the terms of the Creative Commons Attribution License, which permits unrestricted use, distribution, and reproduction in any medium, provided the original author and source are credited. 